\title{
Identification of potential end-members and their apportionment from downstream high-frequency chemical data
}

\author{
Jose Manuel Tunqui Neira ${ }^{1}$, Jean-Marie Mouchel$^{2}$, Gaëlle Tallec ${ }^{3}$, and Vazken Andréassian ${ }^{4}$ \\ ${ }^{1}$ Irstea \\ ${ }^{2}$ University P\&M Curie \\ ${ }^{3}$ INRAE \\ ${ }^{4}$ Cemagref
}

March 9, 2021

\begin{abstract}
High-frequency chemical measurements in streamwater give detailed information on the different hydrochemical processes occurring in the catchment. They can provide clues about the end-members (water sources) whose mixing produces the ionic stream concentrations observed. To identify and quantify the end-members and their respective contribution to streamwater chemistry, we developed a new methodology, termed "IQEA" (Identification and Quantification of End-members and their Apportionment). It consists in the resolution by a minimization process of an objective function based on downstream highfrequency chemical data and the size of the shape of a pre-defined fixed number of three end-members. We applied the IQEA method on the high-frequency concentration dataset of nitrates and calcium from the ORACLE-Orgeval Observatory in France. The results were compared with field data obtained from various potential end-members. The IQEA methodology yielded robust and very satisfactory results, apart from an exceptional flood event that occurred during the 2 years of measurements used in this study. While the IQEA model treats concentration and discharge datasets independently, its results show a strong relationship between the dominant end-member computed and the hydrological features.
\end{abstract}

\section{Hosted file}

main_text.pdf available at https://authorea.com/users/379366/articles/512750-identificationof-potential-end-members-and-their-apportionment-from-downstream-high-frequency-

chemical-data 


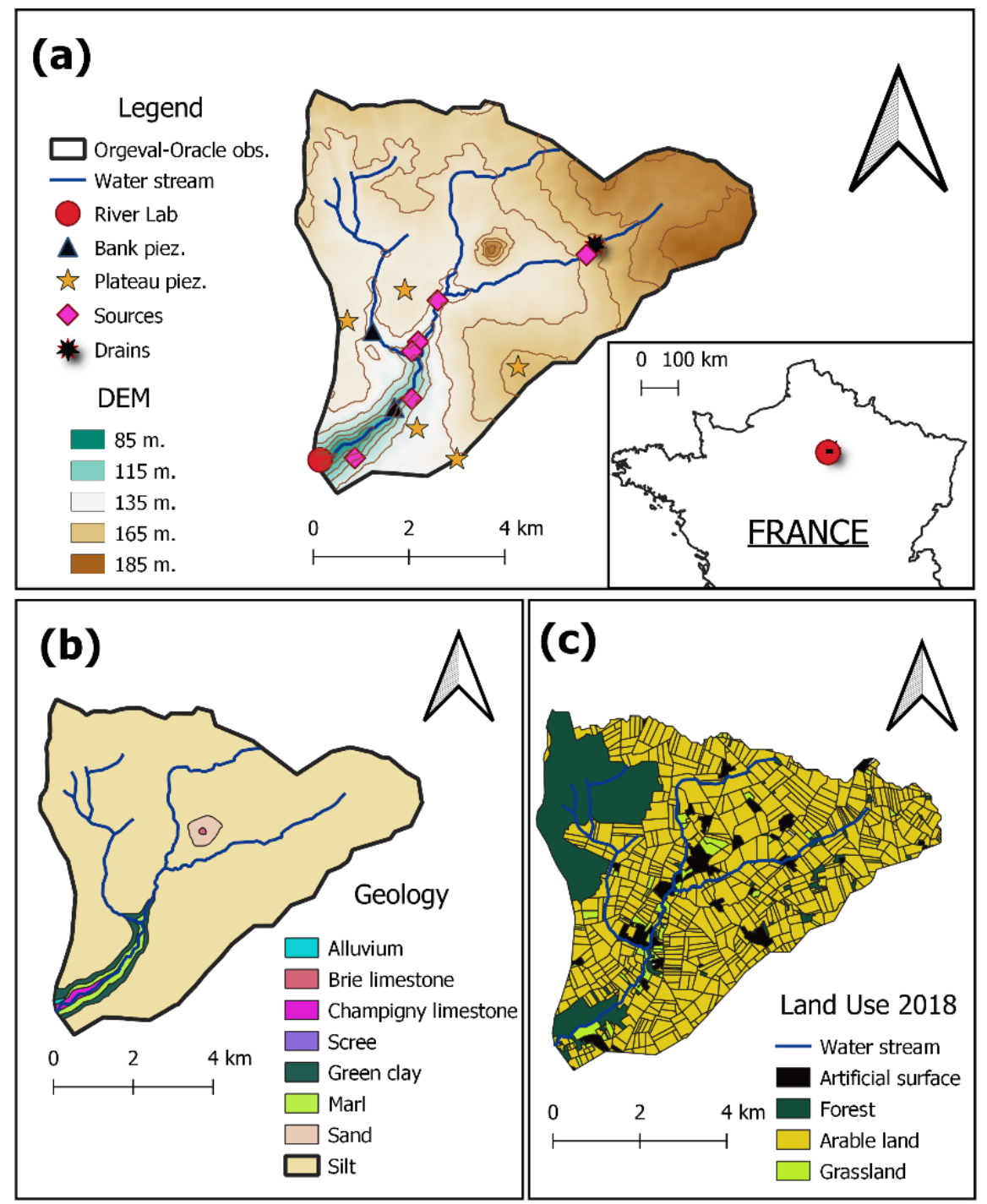



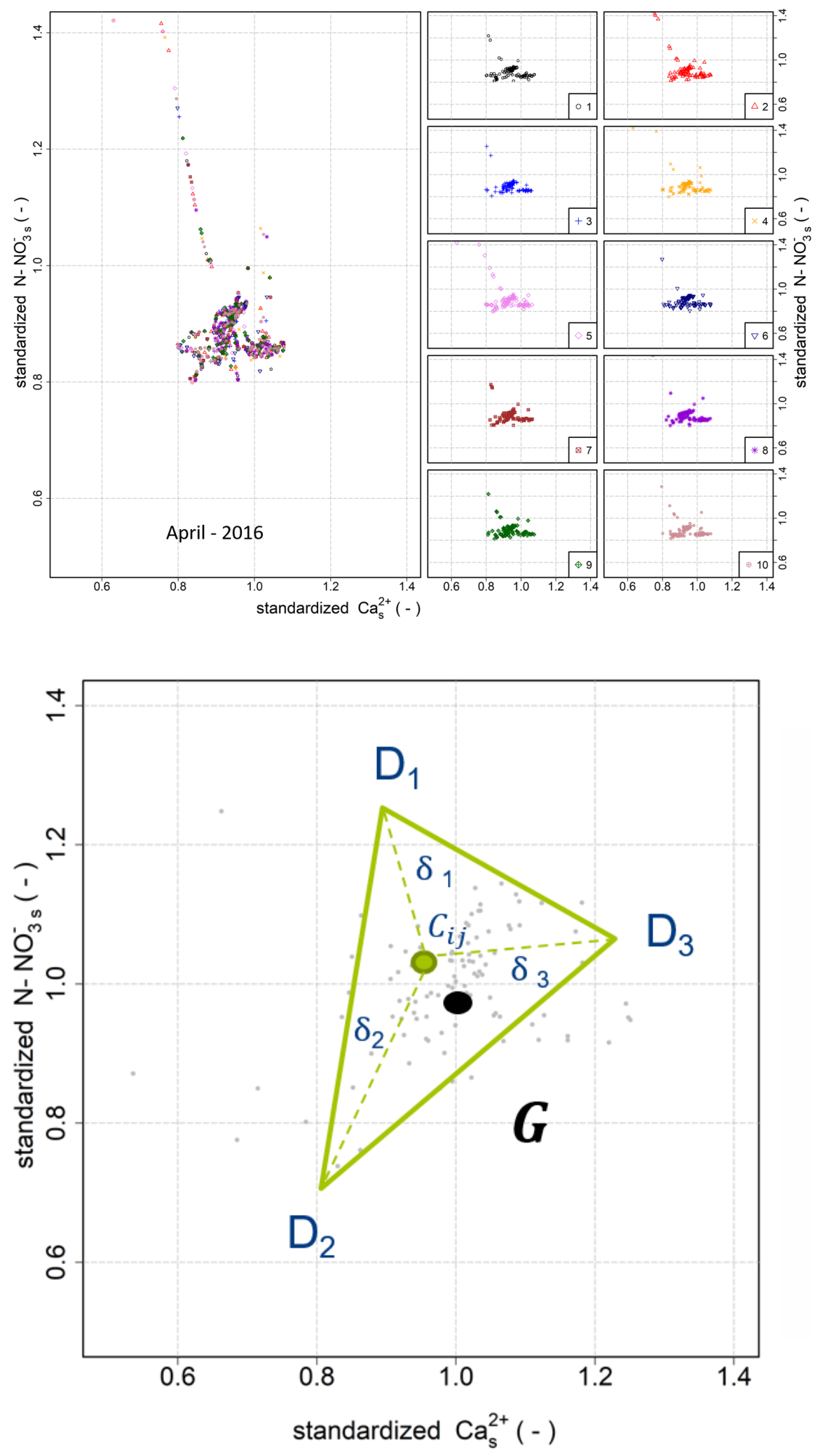

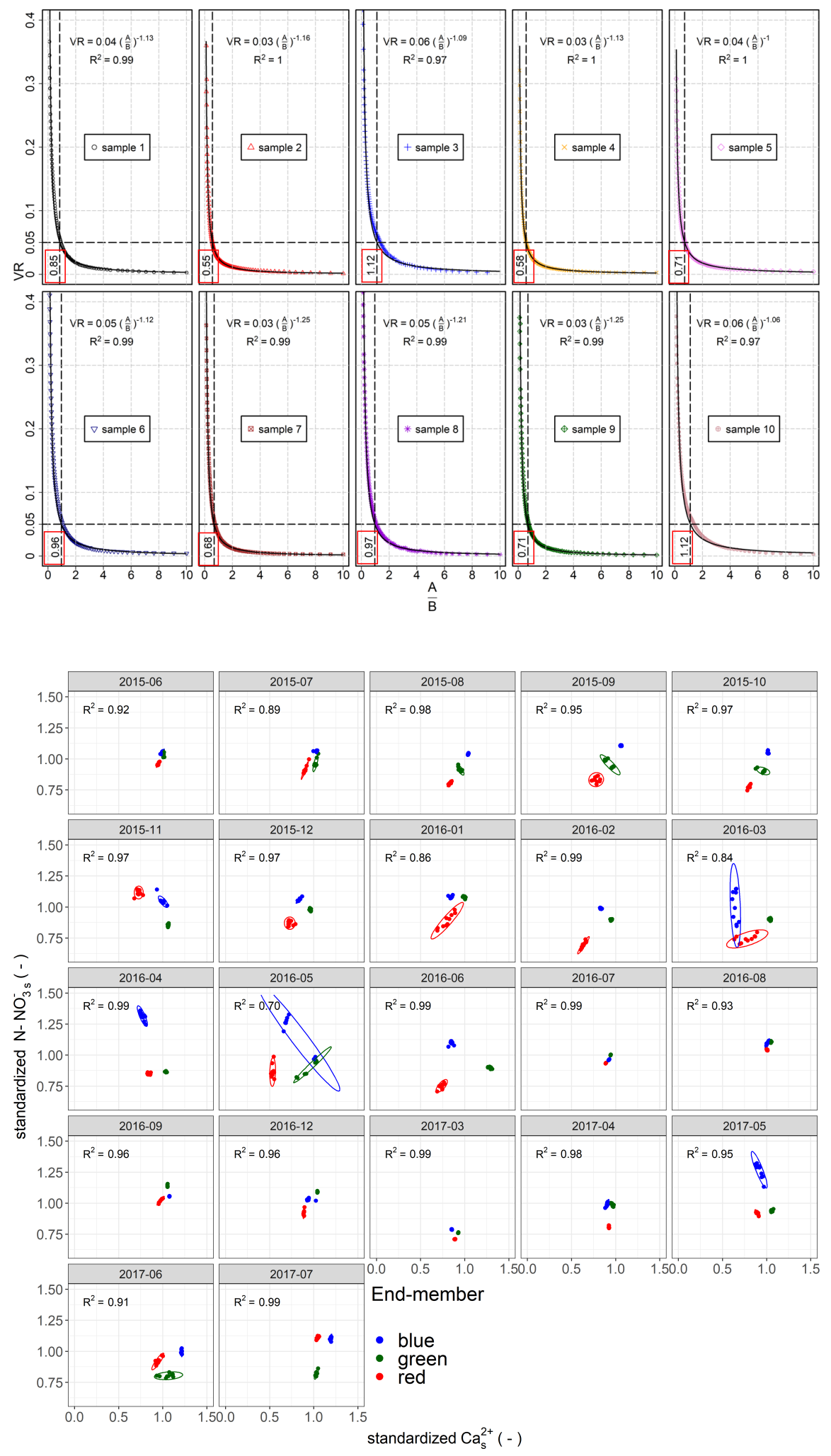

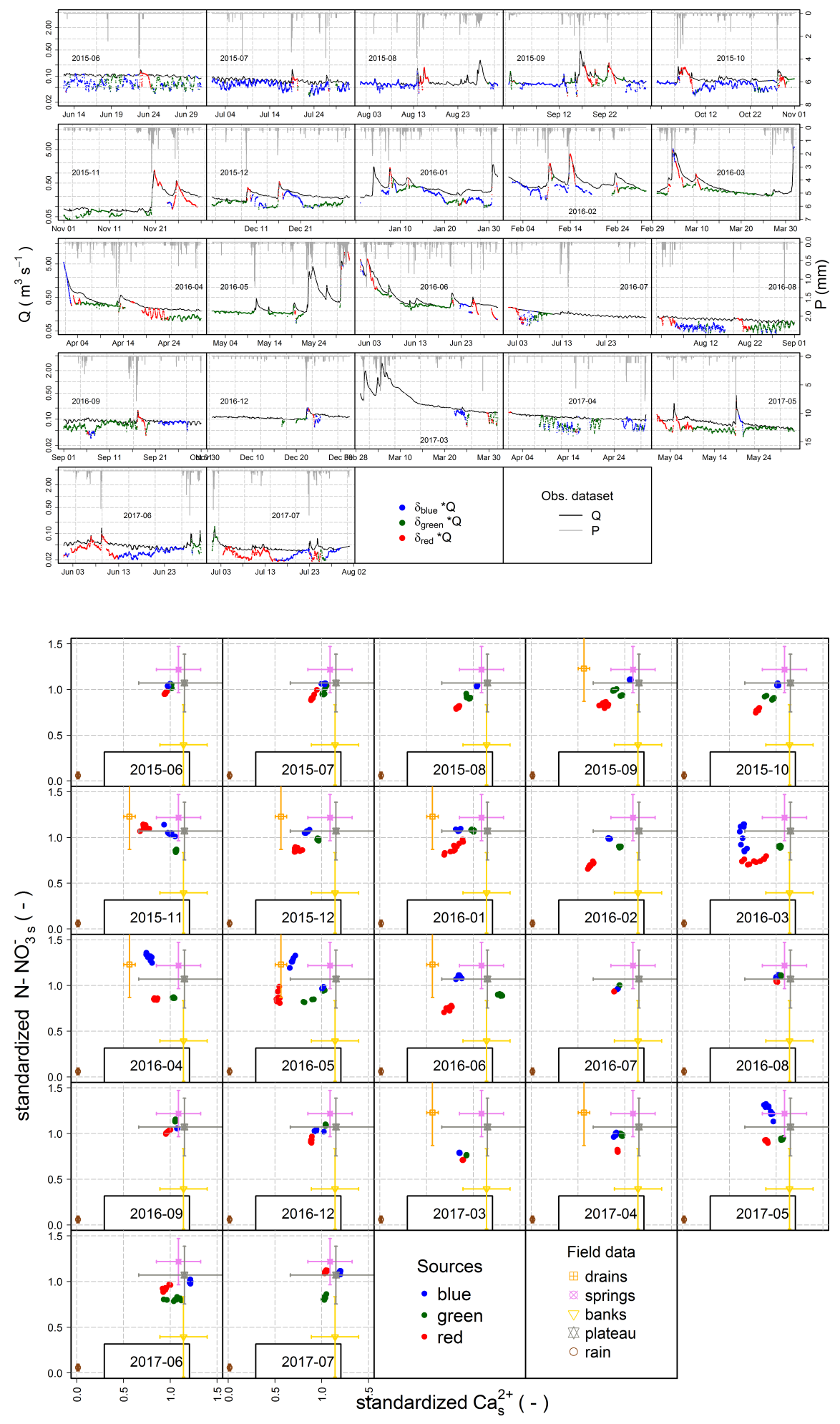


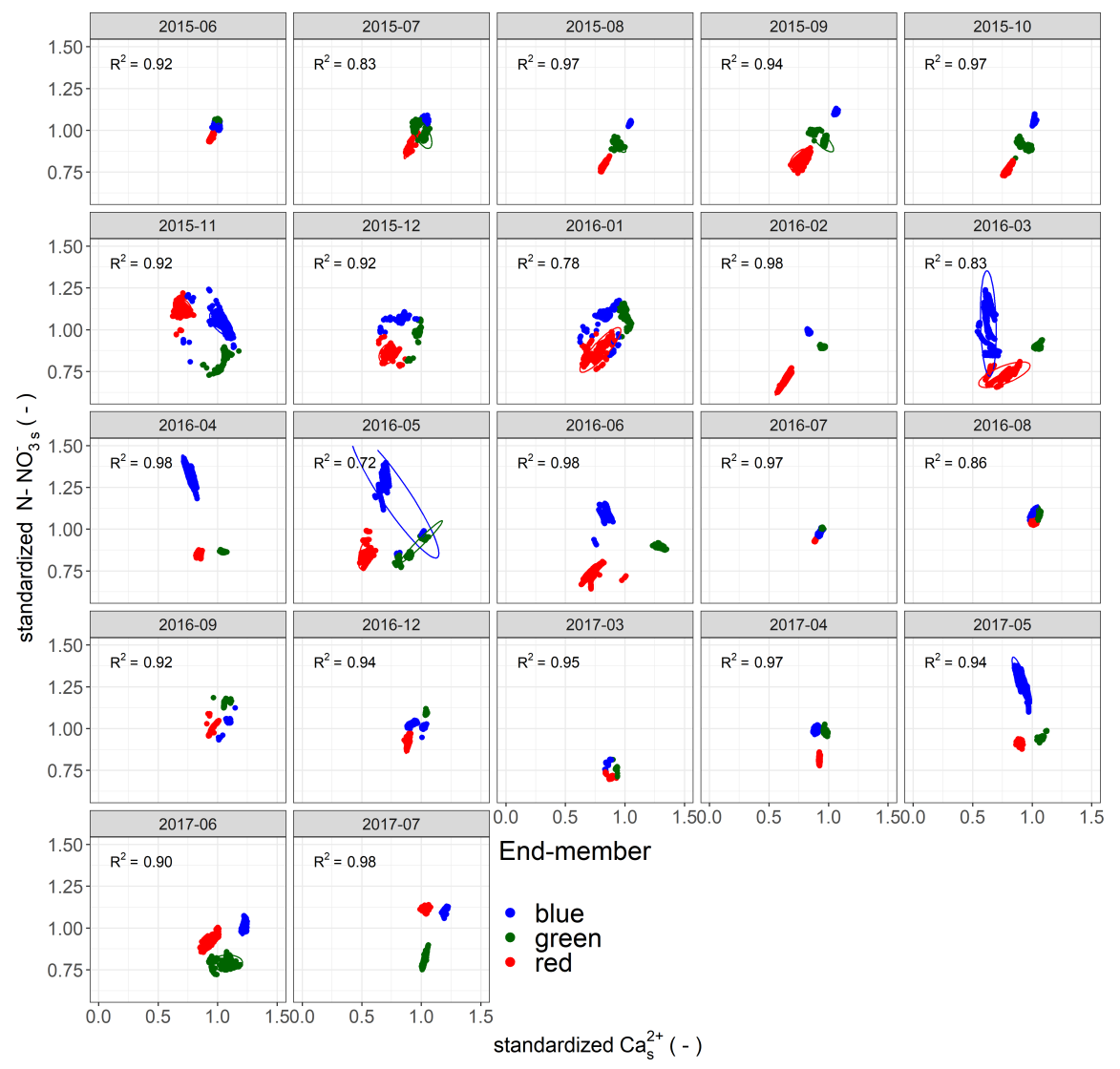

